\title{
In Vitro and in Vivo Effects of Nitrofurantoin on Experimental Toxoplasmosis
}

\author{
Seon-Ju Yeo', ChunMei Jin², SungYeon Kim³ ${ }^{3}$ Hyun Park,* \\ ${ }^{1}$ Zoonosis Research Center, Department of Infection Biology, School of Medicine, Wonkwang University, Iksan 54538, Korea; ${ }^{2}$ Key Laboratory of \\ Natural Resources of the Changbai Mountain and Functional Molecules, Affiliated Ministry of Education, Yanbian University College of Pharmacy, \\ Yanji 133002, PR China; ${ }^{3}$ College of Pharmacy, Wonkwang University, Iksan 54538, Korea
}

\begin{abstract}
Toxoplasma gondii is an important opportunistic pathogen that causes toxoplasmosis, which has very few therapeutic treatment options. The most effective therapy is a combination of pyrimethamine and sulfadiazine; however, their utility is limited because of drug toxicity and serious side effects. For these reasons, new drugs with lower toxicity are urgently needed. In this study, the compound, (Z)-1-[(5-nitrofuran-2-yl)methyleneamino]-imidazolidine-2,4-dione (nitrofurantoin), showed anti-T. gondii effects in vitro and in vivo. In HeLa cells, the selectivity of nitrofurantoin was 2.3, which was greater than that of pyrimethamine (0.9). In $T$. gondii-infected female ICR mice, the inhibition rate of $T$. gondii growth in the peritoneal cavity was $44.7 \%$ compared to the negative control group after 4-day treatment with $100 \mathrm{mg} / \mathrm{kg}$ of nitrofurantoin. In addition, hematology indicators showed that $T$. gondii infection-induced serum alanine aminotransferase (ALT) and aspartate aminotransferase (AST) levels, biochemical parameters involved in liver injury, were reduced by nitrofurantoin significantly. Moreover, nitrofurantoin exerted significant effects on the index of antioxidant status, i.e., malondialdehyde (MDA) and glutathione (GSH). The nitrofurantoin-treated group inhibited the $T$. gondii-induced MDA levels while alleviating the decrease in GSH levels. Thus, nitrofurantoin is a potential anti-T. gondii candidate for clinical application.
\end{abstract}

Key words: Toxoplasma gondii, nitrofurantoin, selectivity, therapeutic efficacy, mouse, HeLa cell

\section{INTRUDUCTION}

Toxoplasma gondii is the causative agent of toxoplasmosis, one of the most severe infectious diseases worldwide, and infects members of the Felidae family and a wide range of intermediate hosts, including warm-blooded animals and humans [1]. Toxoplasmosis can lead to a congenital disease and abortion in humans and domestic animals. In humans, the infection is usually subclinical; however, cervical lymphadenopathy or ocular disease can be present in some patients. Typical clinical symptoms of congenital toxoplasmosis, as proposed by Sabin in 1942 [2], include hydrocephalus or microcephalus, intracerebral calcification, and chorioretinitis. In addition, acquired toxoplasmosis can manifest itself in a variety of places, such as on lymph nodes, liver, heart, lungs, and skeleton [3].

After Sabin and Warren [4] reported the effectiveness of sul-

\footnotetext{
- Received 27 January 2016, revised 10 March 2016, accepted 13 March 2016.

*Corresponding author (hyunpk@wku.ac.kr)

(c) 2016, Korean Society for Parasitology and Tropical Medicine

This is an Open Access article distributed under the terms of the Creative Commons Attribution Non-Commercial License (http://creativecommons.org/licenses/by-nc/3.0) which permits unrestricted non-commercial use, distribution, and reproduction in any medium, provided the original work is properly cited.
}

fonamides against murine toxoplasmosis, Eyles and Coleman [5] discovered the synergistic effect of combined therapy with sulfonamides and pyrimethamine, which has since been a standard treatment for toxoplasmosis in humans. Since 1958, when it was shown that spiramycin has anti-Toxoplasma activity in mice [6], it has been a recommended treatment for pregnant women, to reduce transmission of the parasite from mother to fetus [7]. In addition, clindamycin showed antiToxoplasma activity in conjunction with other drugs, especially in patients allergic to sulfonamides [8,9]. However, adverse effects of sulfadiazine plus pyrimethamine, or clindamycin plus pyrimethamine, such as skin rash, fever, and bone marrow suppression, are frequently observed [10-12]. Therefore, the development of alternative therapies with fewer allergic and adverse effects to treat toxoplasmosis is necessary.

Nitrofurantoin, (Z)-1-[(5-nitrofuran-2-yl)methyleneamino]imidazolidine-2,4-dione (Fig. 1), is a newly synthesized derivative of imidazolidine-2,4-dione. Although it had been reported that imidazolidine-2,4-dione derivatives have biological activities in vitro and in vivo, their effects against $T$. gondii have not been investigated. Therefore, in the present study, nitrofurantoin was investigated for anti-T. gondii effects in vitro and in vivo. 


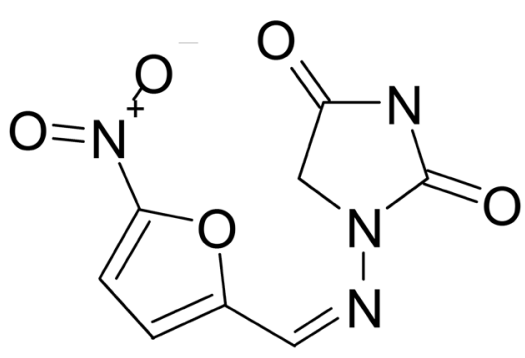

Fig. 1. The chemical structure of nitrofurantoin.

\section{MATERIALS AND METHODS}

\section{Drugs and reagents}

Nitrofurantoin and pyrimethamine were purchased from Sigma-Aldrich Chemical Co. (St. Louis, Missouri, USA). The CellTiter 96 AQueous One Solution Cell Proliferation Assay kit was purchased from Promega Corporation (Madison, Wisconsin, USA). All the sera, antibiotics, and RPMI 1640 for cell culture were obtained from Invitrogen (Grand Island, New York, USA). All the chemicals were of reagent grade.

\section{Cell culture and T. gondii maintenance}

HeLa cells were cultured in RPMI 1640 medium supplemented with 10\% heat-inactivated fetal bovine serum, 100 units $/ \mathrm{ml}$ penicillin, and $100 \mu \mathrm{l} / \mathrm{ml}$ streptomycin with $5 \% \mathrm{CO}_{2}$ at $37^{\circ} \mathrm{C}$. T. gondii (RH strain) was maintained in female ICR mice (Koatech, Pyeongtaek, South Korea), and tachyzoites were obtained from peritoneal fluid.

\section{Cell proliferation assay}

A 3-(4,5-dimethylthiazol-zyl)-5-(3-carboxymethoxyphenyl)2-(4-sulfophenyl)-2H-tetrazolium, inner salt (MTS) assay was used to determine cell proliferation by the CellTiter 96 AQueous One Solution Cell Proliferation Assay kit. HeLa cells were grown and infected with $T$. gondii for $24 \mathrm{hr}$ in a 96-well microplate, and then treated with drugs. After $24 \mathrm{hr}, 20 \mu \mathrm{l}$ of MTS solution was added directly into culture wells, followed by incubating for $1.5 \mathrm{hr}$ at $37^{\circ} \mathrm{C}$ and measuring the absorbance at $490 \mathrm{~nm}$ in a microplate reader. Cell viability was expressed as a percentage of the control value.

\section{Drug selectivity}

Drug selectivity and individual effective concentrations $\left(\mathrm{EC}_{50}\right)$ were determined as previously described [13]. For nitrofurantoin, the selectivity was calculated by the formula:
Selectivity $=$ HeLa cell $\mathrm{EC}_{50} /$ T. gondii $\mathrm{EC}_{50}$.

\section{Animal treatment}

Female ICR mice (6-week-old, 5 mice/group) were injected with $1 \times 10^{5}$ tachyzoites in the abdominal cavity. Mice were separated into 4 groups: normal (no T. gondii), negative control (T. gondii and water), positive control (T. gondii and pyrimethamine), and drug treated (T. gondii and nitrofurantoin). After infection for $2 \mathrm{hr}$, negative control, positive control, and drug-treated groups were administered $300 \mu \mathrm{l}$ of water, pyrimethamine, or nitrofurantoin, respectively, once/day for 4 days. Animals were sacrificed 4 days post infection. Ascites fluid was drawn for determining tachyzoite proliferation. Spleens and livers were weighed and then lipid peroxidation (LPO) and glutathione (GSH) levels were measured in the livers.

\section{LPO assay}

LPO activity was measured by determining malondialdehyde (MDA) levels using thiobarbituric acid as described previously [14]. Liver homogenate was added to $0.2 \mathrm{ml}$ of SDS (8.1\%), $1.5 \mathrm{ml}$ of thiobarbituric acid $(0.67 \%), 1.5 \mathrm{ml}$ of acetic acid (pH 3.5), and $0.6 \mathrm{ml}$ of water. After incubation at $95^{\circ} \mathrm{C}$ for $1 \mathrm{hr}$, it was cooled to room temperature. After adding $5 \mathrm{mk}$ of n-butanol, the samples were centrifuged at 4,000 rpm for $10 \mathrm{~min}$, and the absorbance of the organic layer was measured at $532 \mathrm{~nm}$. Tetraethoxypropane was used in place of the liver homogenate for the standard.

\section{GSH assay}

Liver GSH was measured using an enzymatic recycling method [15]. The liver was pulverized in $8 \mathrm{ml}$ of buffer $(1 \mathrm{M}$ $\mathrm{HClO}_{4}$ and $2 \mathrm{mM}$ EDTA) using a Polytron homogenizer. The homogenate was centrifuged at 5,000 rpm for $5 \mathrm{~min}$, and the supernatant was transferred to a semi-micro cuvette. Phosphate buffer (0.125 M phosphate, $6.3 \mathrm{mM}$ EDTA, pH 7.5), NADPH $(0.3 \mathrm{mM}, 0.7 \mathrm{ml})$, and 5,5'-dithio-bis-(2-nitrobenzoic acid) $(6 \mathrm{mM}, 0.1 \mathrm{ml})$ were then added to the supernatant, followed by mixing and incubating at room temperature for 4 min. Finally, glutathione reductase (50 units $/ \mathrm{ml}$ ) was added, and the absorbance was measured at $412 \mathrm{~nm}$.

\section{Alanine aminotransferase (ALT) and aspartate aminotransferase (AST) levels}

Serum levels of AST and ALT were measured as previously described [16]. Briefly, ALT or AST substrate was incubated 
with serum at $37^{\circ} \mathrm{C}$ for $30 \mathrm{~min}$ or $60 \mathrm{~min}$, followed by the addition of 2,4-dinitrophenylhydrazine at room temperature for $20 \mathrm{~min}$. $\mathrm{NaOH}$ was then added and the mixture incubated for $30 \mathrm{~min}$ followed by measuring the absorbance at $520 \mathrm{~nm}$.

\section{Statistical analysis}

Statistical analysis was performed by the Student's $t$-test. Differences were considered to be significant at $P<0.05$.

\section{RESULTS}

\section{Selectivity of nitrofurantoin in vitro}

In our study, the system for T. gondii drug screening has been used in vitro, which involved cell viability methods to calculate nitrofurantoin selectivity [13]. The selectivity reflects the efficacy of the test compound against T. gondii and toxicity for host cells. The selectivity of nitrofurantoin and pyrimethamine was measured in HeLa cells and was determined to be 2.3 and 0.9 , respectively (Table 1 ). The effect of nitrofurantoin on cell proliferation after infection with T. gondii is shown in Fig. 2. Nitrofurantoin showed dose-dependent inhibition of T. gondii infection; concentrations of 5, 10, 20, and $40 \mu \mathrm{M}$ resulted in $17,30,58$, and $80 \%$ inhibition, respectively, compared to the negative-control group. In addition, the $\mathrm{EC}_{50}$ of nitrofurantoin against $T$. gondii was calculated to be $14.7 \mu \mathrm{M}$, and that for HeLa cells was $33.1 \mu \mathrm{M}$ (data not shown). Nitrofurantoin had a higher selectivity than pyrimethamine, and showed good efficacy as an anti-T. gondii compound in vitro.

\section{Effect of nitrofurantoin on liver and spleen weights}

The relative liver weight of all groups did not change significantly compared with the normal group, but that of the spleen was changed. Compared with the normal group, the relative spleen weight of the T. gondii-negative, nitrofurantoin, and pyrimethamine groups was significantly increased to 215,147 , and $214 \%$, respectively. When the nitrofurantoin group was compared to the T. gondii-negative group, these increases were reduced to $43 \%$, whereas pyrimethamine did not show this effect.

Table 1. Selectivity of nitrofurantoin in HeLa cells

\begin{tabular}{lccc}
\hline & $\begin{array}{c}\text { EC } 50 \text { in HeLa cells } \\
(\mu \mathrm{M})\end{array}$ & $\begin{array}{c}\text { EC } 50 \text { in T. gondii } \\
(\mu \mathrm{M})\end{array}$ & Selectivity \\
\hline Nitrofurantoin & 33.1 & 14.7 & 2.3 \\
Pyrimethamine & 760 & 850 & 0.9 \\
\hline
\end{tabular}

\section{Therapeutic efficacy of nitrofurantoin against $T$. gondii in} vivo

Our in vivo model used 6-week-old mice; however, 4-weekold mice were used in our previous study [17], and we therefore repeated the determination of the optimal dose of the positive-control compound, pyrimethamine, for this study. We found $20 \mathrm{mg} / \mathrm{kg}$ pyrimethamine to be an optimally effective and safe dose (data not shown). Mice were sacrificed 4 days post infection, and ascites fluid was used to determine tachyzoite proliferation. The dose-dependent effects of nitrofurantoin (orally 20, 50, and $100 \mathrm{mg} / \mathrm{kg}$ ) in mice were first examined. The lower concentrations, 20 and $50 \mathrm{mg} / \mathrm{kg}$, of nitrofurantoin did not show any anti-T. gondii effect in the peritoneal cavity, whereas $100 \mathrm{mg} / \mathrm{kg}$ dose significantly reduced the tachyzoite number in the peritoneal cavity (Fig. 3). Based on these results, $20 \mathrm{mg} / \mathrm{kg}$ pyrimethamine and $100 \mathrm{mg} / \mathrm{kg}$ nitrofurantoin were used in our in vivo experiment, even though the nitrofurantoin concentration was higher than that of pyrimethamine. The numbers of tachyzoites in the peritoneal cavity of $T$. gondii-negative group, pyrimethamine-treated positive group, and nitrofurantoin-treated group were 105.7, 22.9, $104.8,94.5$, and $58.5\left(\times 10^{6}\right)$, respectively. The inhibition rate of $T$. gondii growth in the peritoneal cavity was significantly different (44.7\%) compared to the negative group after treatment with $100 \mathrm{mg} / \mathrm{kg}$ nitrofurantoin. However, this inhibition was not significantly better than that of the group with $20 \mathrm{mg} /$ $\mathrm{kg}$ pyrimethamine treatment (78.3\%). These results suggested

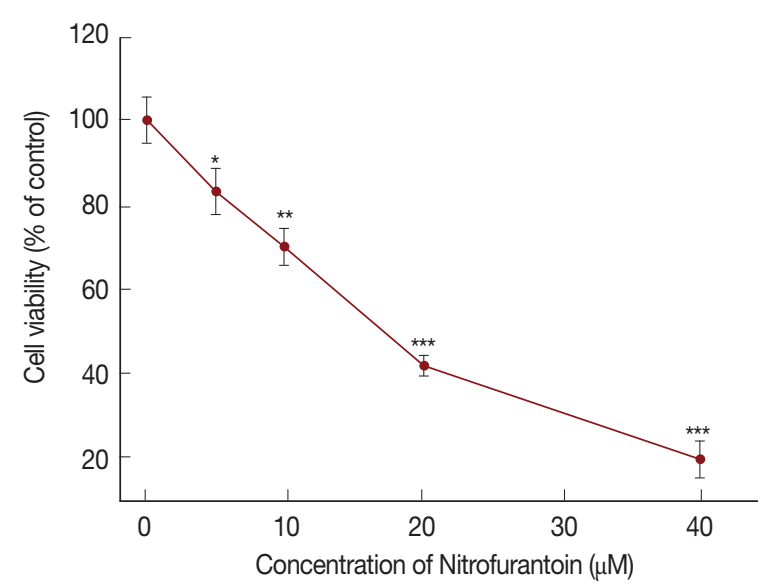

Fig. 2. The effect of nitrofurantoin on cell proliferation after infection with T. gondii by MTS assay in HeLa cells. The data are presented as means \pm SD. The experiments were performed in triplicate. Statistical analysis was performed using the Student's $t$-test. ${ }^{\star} P<0.05,{ }^{* \star} P<0.01$, and ${ }^{* *} P<0.001$ were considered significant relative to the negative control. 


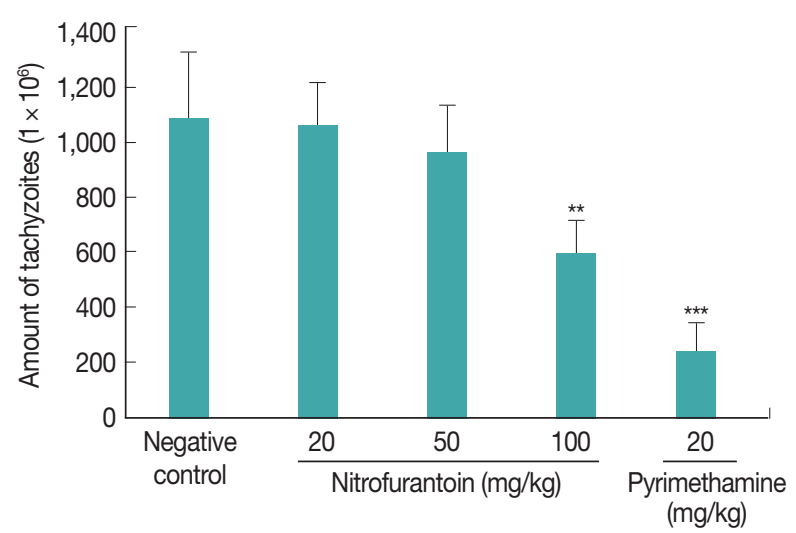

Fig. 3. Number of tachyzoites in the mouse peritoneal cavity. After mice were infected with T. gondii (105/mouse) for $2 \mathrm{hr}$, the negative-control, positive-control, and nitrofurantoin-treated groups were treated orally by gavage once per day for 4 days with water, $20 \mathrm{mg} / \mathrm{kg}$ pyrimethamine, or nitrofurantoin $(20,50$, and $100 \mathrm{mg} / \mathrm{kg}$ ), respectively. All mice were sacrificed 4 days post infection, and tachyzoites were harvested from peritoneal cavities (5 mice/group). ${ }^{\star *} P<0.01$ and ${ }^{* \star *} P<0.001$ were considered significant compared to the negative control.

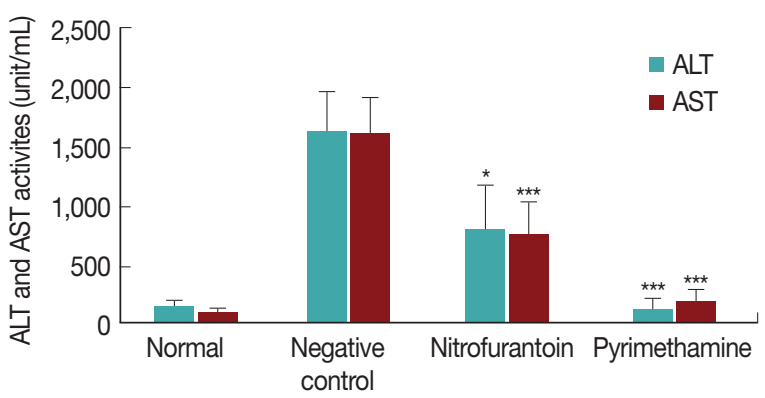

Fig. 4. Serum alanine aminotransferase (ALT) and aspartate aminotransferase (AST) levels in ICR mice after treatment with T. gondii, nitrofurantoin, and pyrimethamine. Mice received an abdominal cavity injection with tachyzoites. After infection for $2 \mathrm{hr}$, negative-control, positive-control, and drug-treated groups were orally administered $300 \mu \mathrm{l}$ water, pyrimethamine, and nitrofurantoin, respectively, once per day for 4 days. The serum levels of AST and ALT were determined by a colorimetric assay. The values are means $\pm S D(n=5)$, and the data were analyzed by Student's $t$ test. ${ }^{\star} P<0.05$ and ${ }^{\star \star \star} P<0.001$ were considered significant relative to the negative-control group.

that nitrofurantoin produced a good anti-T. gondii effect in mouse peritoneal cavities.

\section{Effect of nitrofurantoin on ALT and AST levels in T. gondii- infected mice}

During natural infections, T. gondii initially crosses the intestinal epithelium, disseminates into deep tissues, and enters the circulation, which leads to hepatotoxicity and increase in se-

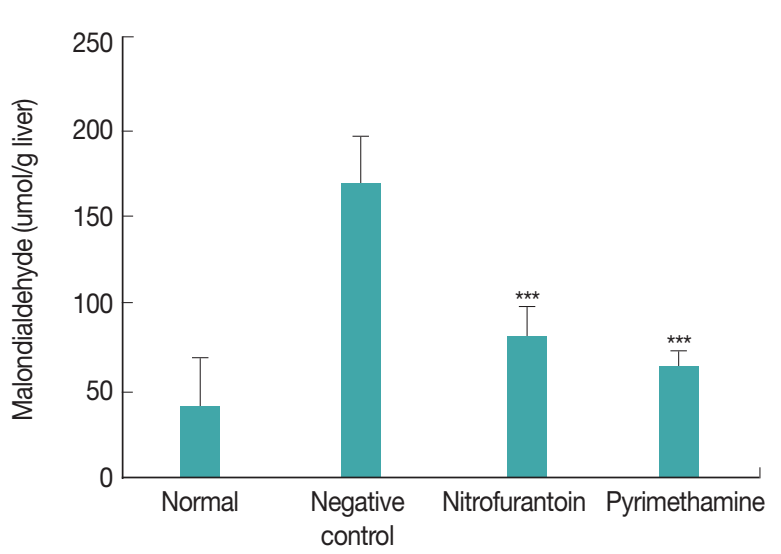

Fig. 5. Effects of nitrofurantoin on malondialdehyde levels in livers of female ICR mice. The malondialdehyde content of the liver was determined after 4 days of treatment. The values are means \pm SD $(\mathrm{n}=5)$, and the data were analyzed by Student's $t$-test. ${ }^{* \star} P<0.001$ was considered significant relative to the negative-control group.

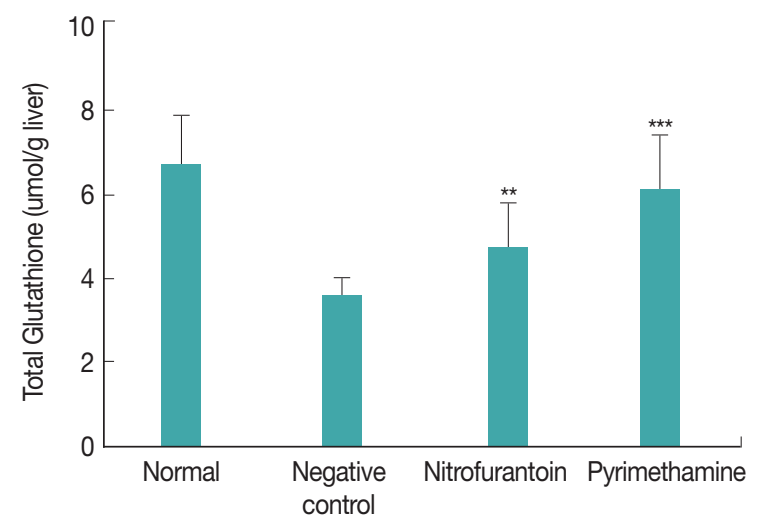

Fig. 6. Effects of nitrofurantoin on glutathione levels in the livers of female ICR mice. The total glutathione content of the liver was determined after 4 days of treatment. The values are means \pm SD $(\mathrm{n}=5)$, and the data were analyzed by Student's $t$-test. ${ }^{\star \star} P<0.01$ and ${ }^{\star \star *} P<0.001$ were considered significant compared with the negative-control group.

rum AST and ALT levels. The serum ALT and AST levels, which indicate hepatotoxicity, are shown in Fig. 4. AST and ALT levels were elevated in the negative group and nitrofurantoin-treated group, as compared with the normal group (Fig. 4). The AST (53\%) and ALT (51\%) levels were reduced significantly after nitrofurantoin was administered to the negative group, although their levels were not significantly less than those in the pyrimethamine group.

\section{Effect of nitrofurantoin on MDA levels in T. gondii-infected livers}

To observe the effects of nitrofurantoin on cell damage, 
malondialdehyde (MDA), which is a product of LPO and an index of oxidative damage, was assayed by using thiobarbituric acid. The MDA level was significantly decreased to $52 \%$ compared with the negative group when treated with $100 \mathrm{mg} / \mathrm{kg}$ nitrofurantoin (Fig. 5), which is similar to that observed in the pyrimethamine group.

\section{Effect of nitrofurantoin on GSH levels in T. gondii-infected livers}

We also measured the level of GSH, one of the most important antioxidant molecules in the liver. The normal GSH level was usually maintained at about $6.61 \pm 1.23 \mu \mathrm{mol} / \mathrm{g}$, but the infected group showed a $65 \%$ decrease to about $4.32 \pm 1.55$ $\mu \mathrm{mol} / \mathrm{g}$, compared to the normal group. However, the GSH level of the nitrofurantoin-treated group significantly increased by $30 \%$ compared to that of the negative group (Fig. 6).

\section{DISCUSSION}

It is well known that standard treatment of toxoplasmosis is usually accompanied with severe side effects; thus, identification of alternative therapeutic compounds is urgently needed. In the present study we evaluated the efficacy and toxicity of a new synthetic imidazolidine-2,4-dione derivative, nitrofurantoin, in vitro and in vivo. It had been reported that many imidazolidine-2,4-dione derivatives have biological activities in vitro and in vivo. Some investigators have found that imidazolidine-2,4-dione derivatives exhibit potential antidepressant activity with a mechanism different from that of the tricyclic antidepressants and monoamine oxidase inhibitors[18], and exert an inhibitory effect against the central nervous system, including anxiety-relieving, anticonvulsant, and anti-depressive effects [19]. In addition, some of these derivatives have shown antiarrhythmic activity in chloroform-, barium chloride-, or adrenaline-induced arrhythmia [20]. Moreover, these derivatives have been shown to selectively inhibit human heart chymase [21], and some were identified as fatty acid amide hydrolase inhibitor templates [22], as novel antitumor agents [23], and as potent radiosensitizing agents [24]. However, there have been no studies of nitrofurantoin, especially concerning its anti-T. gondii activities.

In our study, we have developed a simple high-throughput assay for in vitro drug screening [13], which is fast, simple, and effective, compared with other reported methods. The inhibition of the in vitro infection rate of host cells $\left(\mathrm{EC}_{50}\right)$ was deter- mined by the MTS assay to calculate drug selectivity. These measurements reflected the efficacy of nitrofurantoin against $T$. gondii and toxicity for host cells.

In the current study, nitrofurantoin displayed higher selectivity than pyrimethamine in vitro. In contrast, the pyrimethamine inhibition rate was higher than that of nitrofurantoin in vivo. This discrepancy may be because the clinical parameters of pyrimethamine for use against $T$. gondii have been optimized, such as its concentration and side effects.

Pyrimethamine is known to have antimalarial activities and is used clinically in the therapy of toxoplasmosis and human immunodeficiency virus-associated pneumonia. For adults, pyrimethamine is administered at $25 \mathrm{mg}$ per day for 3-4 weeks, whereas children are administered $2 \mathrm{mg} / \mathrm{kg} /$ day for 3 days, and then $1 \mathrm{mg} / \mathrm{kg} /$ day (maximum $25 \mathrm{mg} /$ day) for 4 weeks. In animal models, one study reported using a combination of dapsone and pyrimethamine in which pyrimethamine was administered at $18.5 \mathrm{mg} / \mathrm{kg} /$ day [25]; however, this dosage was previously reported to be non-curative against $T$. gondii infection [26]. It has been reported that $12.5 \mathrm{mg} / \mathrm{kg}$ of pyrimethamine inhibited the growth of tachyzoites by about $55.5 \%$ in 4 days [17]. This result is consistent with the present study in that $20 \mathrm{mg} / \mathrm{kg}$ of pyrimethamine inhibited the growth of tachyzoites by $78.3 \%$.

Toxoplasmosis causes liver pathologies [27], and the significant agreement of serologically positive cases with elevated plasma AST and ALT has been reported [28]. A decrease in GSH activity was detected, while an increase of MDA was observed in T. gondii-infected patients [29]. Therefore, we assessed the plasma activities of ALT, AST, GSH, and MDA in T. gondiiinfected liver homogenates to compare the efficacy of nitrofurantoin to that of pyrimethamine. Previously, we found that 6-trifluoromethyl-2-thiouracil, a potent anti-T.gondii compound, could recover ALT, AST, and MDA to normal level in T. gondii-infected mice but it could not increase the T. gondii- reduced GSH level [30].

In summary, nitrofurantoin showed good anti-toxoplasmosis effects in T. gondii-infected mice. Furthermore, it showed effective protection against $T$. gondii-induced damage in the liver, similar to that of pyrimethamine. Thus, nitrofurantoin is a potentially useful anti-T. gondii candidate drug that could have a therapeutic value for the treatment of toxoplasmosis. Additional studies are needed to determine the pharmacological indices of nitrofurantoin, such as the side effects and chronic toxicity. 


\section{ACKNOWLEDGMENT}

This research was supported by Priority Research Centers Program through the National Research Foundation of Korea (NRF) funded by the Ministry of Education, (NRF-2015 R1A6A1A03032236).

\section{CONFLICT OF INTEREST}

We have no conflict of interest related to this work.

\section{REFERENCES}

1. Tenter AM. Toxoplasma gondii in animals used for human consumption. Mem Inst Oswaldo Cruz 2009; 104: 364-369.

2. Sabin AB, Feldman HA. Chorioretinopathy associated with other evidence of cerebral damage in childhood; a syndrome of unknown etiology separable from congenital toxoplasmosis. J Pediatr 1949; 35: 296-309.

3. Dubey JP, Zarnke R, Thomas NJ, Wong SK, Van Bonn W, Briggs M, Davis JW, Ewing R, Mense M, Kwok OC, Romand S, Thulliez P. Toxoplasma gondii, Neospora caninum, Sarcocystis neurona, and Sarcocystis canis-like infections in marine mammals. Vet Parasitol 2003; 116: 275-296.

4. Sabin AB, Warren J. Therapeutic effectiveness of certain sulfonamide on infection by an intracellular protozoon (Toxoplasma). Proc Soc Exp Biol Med 1942; 51: 19-23.

5. Eyles DE, Coleman N. The effect of metabolites on the antitoxoplasmic action of pyrimethamine and sulfadiazine. Am J Trop Med Hyg 1960; 9: 277-283.

6. Garin JP, Eyles DE. Le traitement de la toxoplasmose experimentale de la souris par la spiramycine. Presse Medicale 1958; 66: 957-958.

7. Desmonts G, Couvreur J. Toxoplasmosis in pregnancy and its transmission to the fetus. Bull N Y Acad Med 1974; 50: 146-159.

8. Dubey JP, Velmurugan GV, Ulrich V, Gill J, Carstensen M, Sundar N, Kwok OC, Thulliez P, Majumdar D, Su C. Transplacental toxoplasmosis in naturally-infected white-tailed deer: isolation and genetic characterisation of Toxoplasma gondii from foetuses of different gestational ages. Int J Parasitol 2008; 38: 1057-1063.

9. Araujo FG, Remington JS. Effect of clindamycin on acute and chronic toxoplasmosis in mice. Antimicrob Agents Chemother 1974; 5: 647-651.

10. Dannemann B, McCutchan JA, Israelski D, Antoniskis D, Leport C, Luft B, Nussbaum J, Clumeck N, Morlat P, Chiu J, Vilde JL, Orellana M, Feigal D, Bartok A, Heseltine P, Leedom J, Remington J. Treatment of toxoplasmic encephalitis in patients with AIDS. A randomized trial comparing pyrimethamine plus clindamycin to pyrimethamine plus sulfadiazine. Ann Intern Med 1992; 116: 33-43.

11. Georgiev VS. Management of toxoplasmosis. Drugs 1994; 48 :
179-188.

12. Luft BJ, Remington JS. Toxoplasmic encephalitis in AIDS. Clin Infect Dis 1992; 15: 211-222.

13. Jin C, Kaewintajuk K, Jiang J, Jeong W, Kamata M, Kim HS, Wataya Y, Park H. Toxoplasma gondii: a simple high-throughput assay for drug screening in vitro. Exp Parasitol 2009; 121: 132-136.

14. Ohkawa H, Ohishi N, Yagi K. Assay for lipid peroxides in animal tissues by thiobarbituric acid reaction. Anal Biochem 1979; 95: 351-358

15. Griffith OW. Determination of glutathione and glutathione disulfide using glutathione reductase and 2-vinylpyridine. Anal Biochem 1980; 106: 207-212.

16. Reitman S, Frankel S. A colorimetric method for the determination of serum glutamic oxalacetic and glutamic pyruvic transaminases. Am J Clin Pathol 1957; 28: 56-63.

17. Jiang JH, Jin CM, Kim YC, Kim HS, Park WC, Park H. Anti-toxoplasmosis effects of oleuropein isolated from Fraxinus rhychophylla. Biol Pharm Bull 2008; 31: 2273-2276.

18. Wessels FL, Schwan TJ, Pong SF. Synthesis and antidepressant activity of 5-(4-dimethylaminobenzyl)imidazolidine-2,4-dione. J Pharm Sci 1980; 69: 1102-1104.

19. Zejc A, Kiec-Kononowicz K, Chlon G, Kleinrok Z, Kolasa K, Pietrasiewicz T, Czechowska G. Synthesis and pharmacological properties of diphenylimidazolidine acetic and propionic acids derivatives. Pol J Pharmacol Pharm 1989; 41: 483-493.

20. Kiec-Kononowicz K, Byrtus H, Zejc A, Filipek B, Chevallet P. Synthesis and antiarrhythmic properties of basic amide derivatives of imidazolidine-2,4-dione and pyrrolidine-2,5-dione II. Farmaco 1995; 50: 355-360.

21. Niwata S, Fukami H, Sumida M, Ito A, Kakutani S, Saitoh M, Suzuki K, Imoto M, Shibata H, Imajo S, Kiso Y, Tanaka T, Nakazato H, Ishihara T, Takai S, Yamamoto D, Shiota N, Miyazaki M, Okunishi H, Kinoshita A, Urata H, Arakawa K. Substituted 3-(phenylsulfonyl)-1-phenylimidazolidine-2,4-dione derivatives as novel nonpeptide inhibitors of human heart chymase. J Med Chem 1997; 40: 2156-2163.

22. Muccioli GG, Fazio N, Scriba GK, Poppitz W, Cannata F, Poupaert JH, Wouters J, Lambert DM. Substituted 2-thioxoimidazolidin-4-ones and imidazolidine-2,4-diones as fatty acid amide hydrolase inhibitors templates. J Med Chem 2006; 49: 417-425.

23. Mukherjee A, Dutta S, Chashoo G, Bhagat M, Saxena AK, Sanyal U. Evaluation of fluoren-NU as a novel antitumor agent. Oncol Res 2009; 17: 387-396.

24. Reddy YT, Sekhar KR, Sasi N, Reddy PN, Freeman ML, Crooks PA. Novel substituted (Z)-5-((N-benzyl-1H-indol-3-yl)methylene)imidazolidine-2,4-diones and 5-((N-benzyl-1H-indol-3-yl) methylene)pyrimidine-2,4,6(1H,3H,5H)-triones as potent radio-sensitizing agents. Bioorg Med Chem Lett 2010; 20: 600602.

25. Derouin F, Piketty C, Chastang C, Chau F, Rouveix B, Pocidalo JJ. Anti-Toxoplasma effects of dapsone alone and combined with pyrimethamine. Antimicrob Agents Chemother 1991; 35: 252255. 
26. Piketty C, Derouin F, Rouveix B, Pocidalo JJ. In vivo assessment of antimicrobial agents against Toxoplasma gondii by quantification of parasites in the blood, lungs, and brain of infected mice. Antimicrob Agents Chemother 1990; 34: 1467-1472.

27. Roca B, Calabuig C, Arenas M. Toxoplasmosis and hepatitis. Med Clin (Barc) 1992; 99: 595-596 (in Spanish).

28. Yarim GF, Nisbet C, Oncel T, Cenesiz S, Ciftci G. Serum protein alterations in dogs naturally infected with Toxoplasma gondii. Par- asitol Res 2007; 101: 1197-1202.

29. Karaman U, Celik T, Kiran TR, Colak C, Daldal NU. Malondialdehyde, glutathione, and nitric oxide levels in Toxoplasma gondii seropositive patients. Korean J Parasitol 2008; 46: 293-295.

30. Choi HJ, Yu ST, Lee KI, Choi JK, Chang BY, Kim SY, Ko MH, Song HO, Park H. 6-trifluoromethyl-2-thiouracil possesses antiToxoplasma gondii effect in vitro and in vivo with low hepatotoxicity. Exp Parasitol 2014; 143: 24-29. 